\title{
Reuna
}

\section{AÇÕES DE SUSTENTABILIDADE EM CADEIAS PRODUTIVAS: UMA PESQUISA EM RELAÇÃO À PRODUÇÃO DO CAJU E DO COCO}

\section{SUSTAINABILITY ACTIONS IN PRODUCTIVE CHAINS: A RESEARCH RELATED TO THE CASHEW AND COCONUT PRODUCTION}

http://dx.doi.org/10.21714/2179-8834/2017v22n3p1-18

Ravi Lima Cruz

Universidade de Fortaleza (Unifor), Brasil.

E-mail: ravilima14@gmail.com

\author{
Brenda Alves Alencar \\ Universidade de Fortaleza (Unifor), Brasil. \\ E-mail: alencarenda@hotmail.com \\ Minelle Enéas da Silva \\ Universidade de Fortaleza (Unifor), Brasil. \\ E-mail: minele.adm@gmail.com
}

Submissão: 12 Mar. 2017 Publicação: 06 Nov. 2017. Sistema de avaliação: Double blind review. Centro Universitário UNA, Belo Horizonte - MG, Brasil. Editor geral: Prof. Dr. Gustavo Quiroga Souki

Este artigo encontra-se disponível nos seguintes endereços eletrônicos:

http://revistas.una.br/index.php/reuna/article/view/895

http://dx.doi.org/10.21714/2179-8834/2017v22n3p1-18

\section{RESUMO}

Buscando relacionar ações de sustentabilidade em cadeias produtivas da indústria de alimentos, este estudo tem como objetivo identificar quais ações de sustentabilidade (caso haja) estão sendo praticadas, pelos membros de duas cadeias produtivas no Estado do Ceará. As cadeias de produção escolhidas foram a do Caju e a do Coco. Por meio da pesquisa documental e de entrevistas exploratórias se tem, na análise de conteúdo do material selecionado, a identificação de dois critérios de análise: membros da cadeia produtiva e ações de sustentabilidade. Dentre os resultados do coco é possível compreender como funciona o ciclo de distribuição e comercialização entre os membros, e que, a partir dos resíduos do pós-consumo, os subprodutos servem de matéria-prima para outras indústrias. $\mathrm{Na}$ análise do caju, a partir da identificação da estrutura da cadeia, foram encontradas algumas ações relacionadas à sustentabilidade em pesquisas setoriais realizadas. Tais ações surgem como resultado de exigências de clientes do mercado externo. As duas cadeias apresentam ações de sustentabilidade focadas no ambiental, mas com dificuldades de implementação, o que ainda demonstra fraqueza no engajamento dos membros para se direcionar a sustentabilidade na cadeia produtiva.

Palavras-chave: Sustentabilidade, Cadeia Produtiva, Caju, Coco. 


\section{ABSTRACT}

Seeking to relate sustainability actions in the food supply chain, this study aims to identify which are the sustainable actions (in case there is) that are being applied by the members of two supply chains from the state of Ceará - Brazil. The supply chains chosen were the ones from Cashew and the Coconut. Through desk research and exploratory interviews, two criteria of analysis were used based on the content analysis technique: members of the productive chains and sustainable actions. According to the results of the coconut, it is possible to understand how the distribution cycle and commercialization among the members happen, and that from the post consumption waste, it is used as raw materials for other industries. In the analysis of the cashew, from the identification of the supply chain structure, some actions related to sustainability presented in current researches. These actions were possible influenced consumer's demand. Both have environmental sustainability, although there are still plenty difficulties from them to be implemented, which still show the weakness in the commitment of the members chase towards sustainability.

Keywords: Sustainability, Productive Chain, Cashew, Coconut.

\section{Introdução}

Tem se intensificado, ao longo dos anos, a transição da ênfase empresarial nos aspectos econômicos para uma atuação mais voltada à sustentabilidade. Ainda é imprecisa a literatura sobre sustentabilidade no que se refere à sua conceituação, todavia o que se tem aceito é a existência de três dimensões, que se relacionam: econômica, ambiental e social (ELKINGTON, 2002; 2014). O discurso dos gestores e administradores sobre sustentabilidade é dirigido aos seus funcionários, ao mercado consumidor, aos concorrentes, às Organizações Não Governamentais (ONGs), aos parceiros, e aos órgãos governamentais (CLARO et al., 2008). Nesse sentido, está cada vez mais clara a necessidade de engajamento entre as partes para que, de forma articulada, consigam se direcionar para a sustentabilidade.

De acordo com Sartori et al. (2014), a sustentabilidade é um processo que deve ser estabelecido em longo prazo, pois é necessário haver uma mudança no atual modelo de desenvolvimento. Seguindo esta perspectiva, é necessário desenvolver ações, que estejam considerando tanto os objetivos de mercado quanto os da sociedade, para que seja contínua a relação entre os diversos atores sociais. Há empresas que apenas reagem às pressões externas (GIMENEZ; TACHIZAWA, 2012), e há empresas que são proativas, enxergam o valor que pode ser agregado ao seu produto e ao seu negócio através dessas práticas (GONÇALVES-DIAS et al., 2012). Assim, cabe a cada setor e agrupamento de organizações lidar com as especificidades e buscar um maior envolvimento direcionado à sustentabilidade.

Para alcançar a sustentabilidade é preciso observar demandas da sociedade e, em um contexto de negócio, trabalhar em cima da relação entre empresas. Entende-se por cadeia de suprimento a organização de atores desde a aquisição de sua matéria-prima, produção do produto/serviço ofertado até a entrega ao consumidor final (PIRES, 2007). Por cadeia produtiva se entende um sistema interconectado por fluxos de material, de capital e de informação (DE CASTRO et al., 2002). Desse modo, na literatura se identifica que não há diferença entre cadeia de suprimento e produtiva 
(MORAIS; BARBIERI, 2015). No entanto, para esta pesquisa se utiliza a expressão cadeia produtiva pelo tipo de setor estudado. Relacionada à sustentabilidade, o estudo de cadeias deve considerar diversos aspectos dentre os quais: orientação, continuidade, colaboração, gestão de risco e proatividade (BESKE; SEURING, 2014). Tais características são semelhantes também para o agronegócio, já que Beske et al. (2014) enfatizam suas contribuições para o setor de alimentos.

Com o intuito de relacionar ações de uma dada cadeia à sustentabilidade é necessário reconhecer quem são os envolvidos neste processo e, então, que características estão sendo trabalhadas neste contexto (GOLICIC; SMITH, 2013; SILVA et al., 2015; SILVESTRE, 2015). Para tanto, este trabalho tem como objetivo principal identificar quais ações de sustentabilidade (caso haja) estão sendo praticadas pelos membros de duas cadeias produtivas no Estado do Ceará. As cadeias escolhidas foram a do Caju e a do Coco. O caju foi escolhido por ser um importante símbolo do Nordeste brasileiro, sendo a castanha do caju a fruta mais exportada pelo Ceará (ALICEWEB, 2017). Também é a fruta da qual é produzida a cajuína, bebida típica do nordeste, a qual foi até registrada como patrimônio cultural brasileiro pelo Conselho Consultivo do Patrimônio Cultural, um órgão colegiado do Instituto do Patrimônio Histórico e Artístico Nacional (Iphan) (CODEVASF, 2014).

O coco foi escolhido para esta pesquisa por ser um importante símbolo para o Estado, tendo na água do coco um dos principais produtos consumidos neste tipo de produção. O Ceará é o segundo maior produtor de coco do Brasil, atrás apenas do Estado da Bahia. Apesar dos últimos anos de seca, foi o único Estado a aumentar a produção em mais de 38\%, enquanto que a maioria dos outros Estados houve piora na safra em relação ao ano de 2015 (SIDRA, 2017). Ao considerar o impacto de tais cadeias no contexto socioeconômico do Estado, há potencial contribuição dessas para a sustentabilidade no agronegócio e na região.

Para facilitar a compreensão, esta pesquisa possui quatro partes, além desta introdutória. A próxima seção debate a base teórica que norteou o desenvolvimento da pesquisa tanto na relação entre sustentabilidade e cadeia produtiva, como o foco relativo ao agronegócio. Na terceira seção estão explícitos os procedimentos metodológicos utilizados para a realização da pesquisa. A seção de resultados e discussões traz o conjunto de informações, que foram levantadas e analisadas no sentido de delimitar o mapeamento dos membros e como a sustentabilidade tem sido trabalhada nestas cadeias. Por fim, as conclusões trazem a reflexão final sobre as contribuições desta pesquisa para a área de estudo.

\section{Sustentabilidade na cadeia produtiva}

No debate sobre o relacionamento empresarial, a cadeia de suprimento consiste em todas as partes interessadas de uma empresa que se relacionam a partir de uma atividade principal. Sob esta perspectiva, e tentando aprofundar o estudo sobre relacionamento, Morais e Barbieri (2015) esclarecem que não há diferença significativa entre a cadeia de suprimento e a cadeia produtiva, o que justifica haver na literatura uma quantidade de pesquisas focadas na parte produtiva, mas usando o conceito de cadeia de suprimento. Nesta pesquisa, utiliza-se a expressão cadeia produtiva, uma vez que a ênfase está na produção do agronegócio. Salienta-se, ainda, 
que a base teórica de sustentabilidade em cadeias tem como ênfase o debate sobre cadeia de suprimento, o que norteia os argumentos desta pesquisa.

Para o desenvolvimento de pesquisa sobre cadeia produtiva é importante conhecer os membros que a compõem, tanto para fortalecer as relações com estes para obter um bom gerenciamento de cadeia (GOLICIC; SMITH, 2013; SHARFMAN et al., 2009; BESKE et al., 2014), como também para saber a origem e o destino do produto final, com o intuito de conhecer os processos que ali são realizados. Por exemplo, se um membro da cadeia se envolva em atividades ilegais, que desrespeitem leis ambientais, ou ainda que não respeitem os valores praticados e/ou denigram a reputação da empresa focal, esse membro seria localizado e, então, as medidas necessárias para um melhor funcionamento da cadeia podem ser tomadas. Para Carvalho e Barbieri (2013), isso representa a necessidade de gerir as ações além do ambiente interno, de onde se tem o maior potencial de controle.

Para tanto, deve-se considerar nos processos de desenvolvimento destes serviços ou produtos a definição da Comissão Brundtland (WCED, 1987), que considera o desenvolvimento sustentável como a forma de satisfazer as necessidades da geração presente sem comprometer as necessidades das gerações futuras, já que os recursos são escassos e as necessidades humanas têm se apresentado com poucos limites. Neste contexto, as empresas não podem ser criadas já sabendo que se tornarão inviáveis no futuro próximo, para as novas empresas a orientação para a sustentabilidade deve ser uma motivação potencial. Isso se torna verdadeiro ainda para as atuais empresas, que por meio de novos comportamentos têm a possibilidade de entregar novos resultados na sociedade (ABDALA; BARBIERI, 2014; CARVALHO; BARBIERI, 2012; SILVESTRE, 2016).

Desse modo, entende-se que a preocupação com a sustentabilidade envolve dentre outros aspectos a necessidade de conservação do solo, da água e dos recursos genéticos animais e vegetais, assim, além de não degradar o ambiente, deve ser tecnicamente apropriado, economicamente viável e socialmente aceito (GIORDANO, 2005). Seguindo esta visão, para Silva (2012), o lidar com a sustentabilidade vai além de simplesmente não degradar o meio ambiente, assim deve haver a incorporação de questões mais específicas como a qualidade de vida, colaboração e competitividade empresarial, resultados positivos, tecnologias limpas, utilização racional dos recursos, responsabilidade social, entre outros.

Para que a sustentabilidade possa ser observada sob a perspectiva da produção, esta pode ser aproximada do contexto de cadeia de suprimento/produtiva, uma vez que nenhuma empresa pode ser mais sustentável do que a sua cadeia de relações (BESKE; SEURING, 2014). Neste contexto, surge o conceito de sustentabilidade em cadeia de suprimento (SCS) (Sustainable Supply Chain Management), que seria definida como:

A gestão de material, informações e fluxo de capital, bem como a cooperação entre as empresas ao longo da cadeia de suprimento, com objetivos de todas as dimensões da sustentabilidade (econômico, social e ambiental), em relação ao requerido por consumidores e demais stakeholders (SEURING; MULLER, 2008, p. 1700). 
Para Almeida (2002), essas dimensões conhecidas como triple bottom line, abordam a dimensão ambiental, que incentiva as empresas a considerarem o impacto de suas atividades sobre o meio ambiente, na utilização dos recursos naturais, e repensar sua forma de trabalho; a dimensão social, que avalia o impacto das atividades da empresa sobre a sociedade, abrangendo tanto o ambiente interno da empresa quanto o externo; e a dimensão econômica, que não leva em consideração somente a economia formal, mas também as atividades informais, que fornecem serviços para os indivíduos e grupos e aumentam, assim, a renda monetária e o padrão de vida dos indivíduos.

A sustentabilidade na cadeia de suprimento/produtiva das organizações deve, portanto, referir-se às ações específicas que são tomadas com o objetivo de tornar a cadeia mais sustentável (PAGELL; WU, 2009; PAGELL; SCHEVCHENKO, 2014), não somente seguindo a tradicional ótica de valor econômico, mas considerando valores ambientais e sociais (TAKAHASHI et al. 2015). No Brasil, cada vez mais o estudo sobre o tema tem sido verificado (GOLD, 2016; SILVESTRE, 2016) seja em um contexto de suprimento ou de produção. De acordo com Gold (2016), ao se realizar uma pesquisa na base Scopus é possível observar que há uma tendência de crescimento das pesquisas no país, o que demonstra um novo perfil de pesquisa.

Dentro da cadeia do agronegócio e do setor de alimentos, as práticas de sustentabilidade trazem aspectos positivos como o respeito à legislação ambiental, uso racional de agrotóxicos e recursos hídricos, monitoramento de níveis de contaminação, redução nas emissões de gases na natureza, a priorização do comércio local, da população local e os serviços locais (SOUZA; MORAES, 2012). Para além de observar o debate sobre a relação entre sustentabilidade e cadeia de produção/suprimento, torna-se necessário dar ênfase a algumas especificidades que impactam diretamente na criação de sua aproximação.

Seguindo esta perspectiva, a questão da colaboração, da articulação e da cooperação entre os atores do relacionamento podem ser destacados no sentido de facilitar o engajamento de membros da cadeia (BESKE et al. 2014). Em cada setor econômico, diversas são as características que representam suas atividades. Como apresentado por Silva et al. (2016), por exemplo, o setor de carne bovina representa um das mais complexas cadeias, não pela quantidade de elos existentes, mas pelo conjunto de atores, que geram dificuldade de gestão. Para os autores, a articulação surge como o fator que mais impacta na sustentabilidade do setor, uma vez que o relacionamento precisa ter similares características de organização. No entanto, como ressaltam, muitas vezes, a sua falta prejudica a performance da cadeia.

A partir de tais características, uma vez que uma cadeia produtiva está organizada e se direciona a uma maior articulação entre os atores de um mesmo relacionamento, entende-se haver a possibilidade de inserção de sustentabilidade como um tema a ser compartilhado por todos os envolvidos na cadeia. Como apresentado anteriormente, a sustentabilidade deve ter como base diferentes dimensões, as quais fazem referência e facilitam a integração entre os atores de uma mesma cadeia, por meio da articulação (TOUBOULIC; WALKER, 2015). Para tanto se torna tão evidente a necessidade de ampliar pesquisas, que tragam contribuições para melhor compreender o agronegócio e a sua relação direta com a sustentabilidade, o que no caso desta pesquisa ocorre pela ênfase no coco e no caju, enquanto atividades produtivas de grande impacto socioeconômico. 
O desenvolvimento de práticas sustentáveis pode contribuir para reestruturar os processos de produção, fluxo de materiais e informações, e de acordo com Pusavec et al. (2010) a indústria vem dedicando esforços a favor da sustentabilidade, por meio de mudanças no projeto de seus produtos, desenvolvimento de novos materiais, reuso e reciclagem de materiais e redução de desperdícios, existindo uma prospecção de aumento de interesse dos investidores por indústrias com práticas de sustentabilidade e a aplicação do conceito de 6Rs (remanufaturar; reprojetar; recuperar; reciclar; reutilizar; e reduzir) como a evolução da produção verde e base da produção sustentável. Tais aspectos precisam deixar mais claro como ações sociais e econômicas influenciam em sua efetivação. Para atender ao objetivo proposto, a seguir se apresentam os procedimentos utilizados para a pesquisa.

\section{Procedimentos Metodológicos}

A presente pesquisa assume abordagem qualitativa. Além disso, tem caráter exploratório por proporcionar uma visão geral acerca de determinado assunto. Uma interessante característica da pesquisa exploratória é seu aprofundamento nas temáticas abordadas, que não tenham sido contempladas de forma satisfatória anteriormente, o que contribui para esclarecimentos de questões sobre o assunto (CRESWELL, 2007). Andrade (2002), ao se referir à pesquisa exploratória, destaca algumas finalidades, que seriam: proporcionar maiores informações sobre o assunto pesquisado, facilitar a delimitação do tema, orientar a definição dos objetivos ou até descobrir outro tipo de enfoque para o assunto.

O procedimento central adotado para a coleta de dados deste estudo foi a pesquisa documental, uma vez que utiliza materiais que ainda não receberam uma análise aprofundada, visando assim, selecionar, tratar e interpretar a informação bruta, agregando-lhe valor, a fim de contribuir com a comunidade científica (MARCONI; LAKATOS, 2010). Para esta pesquisa foram coletadas informações a partir de sites, dissertações, artigos científicos, etc., a fim de explorar as cadeias produtivas do Caju e do Coco. Assim, buscou-se identificar os principais membros e a importância de cada um deles, com o intuito de desenvolver um mapeamento, que detalha seu funcionamento desde o plantio até o consumidor final, observando as ações de sustentabilidade existentes nestas cadeias. Esta pesquisa aconteceu entre Agosto de 2016 e Fevereiro de 2017.

A partir das diversas informações coletadas e como forma de torná-las mais próximas da realidade foram realizadas entrevistas com especialistas, de cada setor, no sentido de ratificar, de contrariar ou de adicionar informações àquelas possíveis de se identificar nos documentos. Para tanto, foram contatados pesquisadores da Embrapa (Empresa Brasileira de Pesquisa Aplicada), que no Estado do Ceará, têm pesquisas voltadas para a produção do Caju e do Coco. Além disso, foi contatado um especialista em qualidade, que tem realizado projetos de consultoria junto as duas cadeias. As entrevistas ocorreram em Novembro e Dezembro de 2016, com média de 45 minutos, nos locais solicitados pelos entrevistados. Todas foram transcritas e retornaram aos especialistas para sua conferência e validação.

Foram utilizados dois critérios de análises, de acordo com Silva et al. (2015), a saber: (1) membros da cadeia produtiva - enquanto aqueles que dão suporte à 
organização focal; e (2) ações de sustentabilidade - analisando ações tanto dos membros quanto das organizações focais. Com base nesses critérios foi realizada uma análise de conteúdo seguindo a perspectiva da Bardin (2009), no que se refere à identificar o documento, tratar o conteúdo ali existente e, então, obter unidades de análise que representem o objetivo da pesquisa. A partir de todas as informações coletadas, a seção a seguir apresenta um compilado dos principais resultados no sentido de debater e discutir a sustentabilidade nas cadeias selecionadas.

\section{Resultados e Discussão}

O Caju e o Coco são frutos de extrema relevância econômica e cultural para o Ceará. O caju é um produto bastante comum no Estado e apresenta dois produtos principais, que são altamente comercializados, a castanha de caju que é em maior parte vendida para o mercado externo, cerca de 95\%, segundo o especialista de qualidade, o remanescente é comercializado no comércio local e nacional, e o pedúnculo (parte carnosa do caju), de onde é retirado o insumo para fazer suco, polpa e outros produtos. O pendúnculo é comercializado apenas no mercado nacional devido ao seu baixo valor agregado, ainda segundo esse especialista.

Informações levantadas no site Aliceweb (2017), que faz parte do Ministério da Indústria, Comércio Exterior e Serviços (MDIC), apontam que a castanha do caju foi o $2^{\circ}$ produto mais exportado pelo Ceará em 2016, gerando uma receita de aproximadamente US\$103,206 milhões, o que demonstra a relevância econômica do produto. Segundo o Levantamento Sistemático de Produção Agrícola (LSPA), foram produzidas 30.763 toneladas de castanha de caju no Estado, correspondendo a $38,56 \%$ da produção nacional. Com isso, o Ceará se destaca como o maior produtor de caju do Brasil. No entanto, a produção está reduzindo ano após ano, devido à seca que já se prolonga por mais de cinco anos.

Já o coco, pelo contrário, tem a maior parte de seu consumo no mercado interno, como indicado pelo especialista de qualidade. Segundo o LSPA, no Ceará foram cultivadas mais de 40 mil hectares de coqueirais, o que corresponde a $19 \%$ da área cultivada nacionalmente, da qual boa parte é destinada à produção da água de coco, tanto para atender à demanda nacional, cerca de 350 milhões de litros/ano, como à crescente demanda do mercado internacional, porém ainda pequena. Como identificado na Embrapa, o coco gera alguns subprodutos, como: o óleo de coco, o coco ralado e o leite de coco. Também se pode salientar que o Brasil acabou alcançando a posição de maior produtor mundial nos últimos anos.

\subsection{Membros da cadeia de produção do Coco e suas ações de sustentabilidade}

Quanto aos membros da cadeia, para Rebello et al. (2003), os elementos envolvidos na comercialização do coco in natura são: o produtor, responsável pelas decisões de o que e como produzir; o intermediário, primeiro elo entre o produtor e os outros agentes da comercialização; o atacadista, concentrando a produção de vários produtores e intermediários; o varejista, responsável pela comercialização do produto em pequenas quantidades; e o consumidor, último elo da comercialização do coco. 
Segundo Cavalcante (2012), todo o coco in natura que é produzido possui, basicamente, quatro destinos: as agroindústrias localizadas no próprio Estado, a cidade de Fortaleza, o mercado nacional interno e o mercado externo.

Após a produção dos cocos é preciso que esta seja escoada. Assim, se faz necessário escoá-la aos centros de distribuição para que cheguem aos consumidores em tempo hábil. Para compreender o melhor funcionamento deste ciclo produtivo, encontra-se na Figura 1 o processo de comercialização do coco (in natura, seco ou industrializado), com seus canais e fluxos de produção. Percebe-se haver vários caminhos de escoamento da produção, o que ratifica a existência de amplo envolvimento de agentes neste setor. As informações apresentadas na figura foram complementadas pelas respostas do especialista de qualidade que destacou, por exemplo, o papel da prefeitura como um ator importante na logística verde do coco, uma vez que esta possui em alguns momentos parceria com comerciantes e barracas de praia para coleta dos resíduos. Além disto, o especialista da Embrapa validou a estrutura apresentada como versão inicial da ilustração criada.

Figura 1. Cadeia de produção do Coco

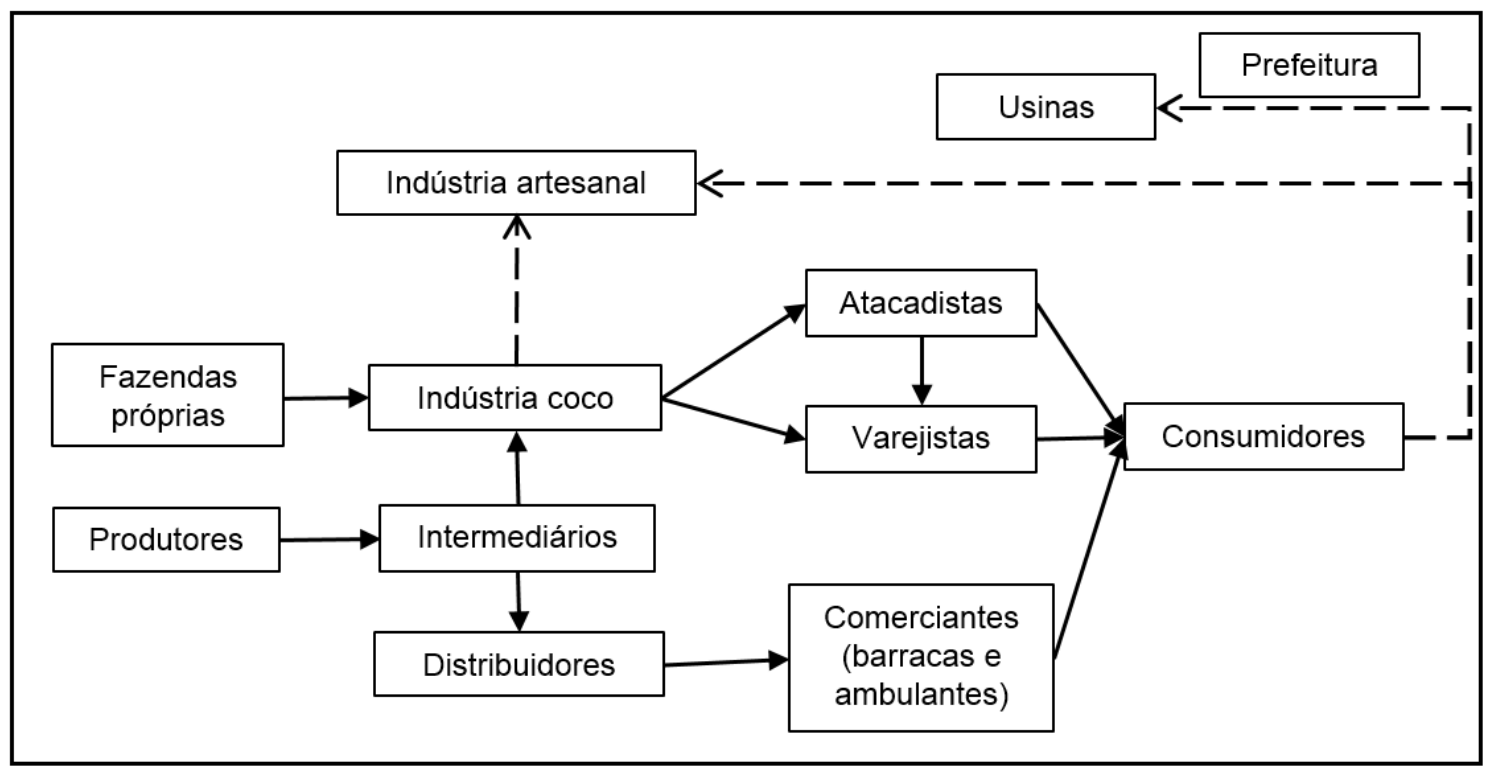

Fonte: Dados de pesquisa (2016)

Conforme a Figura 1, o primeiro membro desta cadeia compreende o produtor de coco que vende, diretamente, às indústrias de processamento, e aos intermediários; ao passo que as indústrias ainda recebem cocos de fazendas próprias. Os intermediários vendem para a indústria e para distribuidores de coco, assim como direto nas CEASAs (Centros de Abastecimento). Na cadeia se percebe que o coco segue por dois canais após as indústrias, é adquirido por varejistas de armazéns e supermercados, ou é adquirido por atacadistas direto das indústrias. Dos distribuidores, o produto chega aos comerciantes (ambulantes e barracas de praia) para venda direta ao consumidor final. Além disso, percebem-se dois fluxos distintos, um de resíduos para a indústria artesanal e outro reverso com o resíduo do consumo final tanto para esta indústria quanto para usinas de biomassa. 
Em relação às ações de sustentabilidade, em alguns lugares já se observa problemas causados por causa da geração de resíduos do coco, que segundo o Instituto ECoco (2016), correspondem a cerca de $85 \%$ do peso do fruto. Com base nessa informação e na Política Nacional de Resíduos Sólidos, que responsabiliza os geradores de resíduos (direto ou indireto) uma das maiores agroindústrias do país, a Ducoco, vem repensando a forma de trabalhar aproveitando ao máximo toda a matéria do coco. Este fato tem sido buscado por outras indústrias de coco. Assim sendo, a principal matéria-prima, a água do coco é engarrafada; sua polpa é usada para a fabricação de leite de coco e coco ralado; o endocarpo (a casca dura), que envolve a parte comestível é utilizado como combustível nas caldeiras de produção; a partir da película, que se encontra entre o endocarpo e a polpa é produzido o óleo de coco e ração animal e, por fim, o mesocarpo, que são as fibras do coco, são fontes de nutrientes para o solo das fazendas.

De acordo com Fontenele (2005), toda essa possibilidade de aplicações de seus produtos e subprodutos atribui uma elevada importância econômica e grande valor a ser agregado à cultura do coqueiro, fazendo com que a agroindústria do coco se firme cada vez mais no Brasil. Para Rocha et al. (2010), os produtos oriundos do aproveitamento das cascas do coco verde são diversos e estes produtos trazem a proposta da sustentabilidade. A partir do coco se podem obter (FONTENELE, 2005; SANTOS et al., 2011):

- Assentos e revestimento internos de veículos, pois a fibra do coco é melhor do que a espuma derivada do petróleo, por ser uma matéria-prima barata, como também por ser ecologicamente correta, resistente e durável.

- Mantas e telas de proteção para o solo, que servem para proteção, controle e recuperação de áreas degradadas.

- Vassouras e Cordas obtidas a partir de meadas de fibras que podem ser mais curtas e de tamanho diferentes.

- Substrato agrícola e peças para jardinagem, como vasos, palitos e placas, dentre outros que substituem os artefatos produzidos com xaxim, palmeira da Mata Atlântica, em extinção, com extração regulamentada por lei.

- Isolante térmico e acústico, a fibra de coco contribui para uma redução substancial dos níveis sonoros, superando largamente os resultados obtidos com a utilização de outros materiais.

- Briquetes, que são produtos de alto poder calorífico, obtido pela compactação dos resíduos de madeira como o pó de serragem e as cascas vegetais como a casca de coco. Este produto é muito utilizado para a geração de energia, sendo considerados uma lenha ou carvão ecológico de alta qualidade.

Além das diversas formas de aproveitamento dos produtos e subprodutos, a cultura do coco apresenta uma série de vantagens econômicas, sociais e ambientais, que se comparada a outras culturas desenvolvidas nas áreas litorâneas, viabilizam a atividade tornando-a rentável. Como identificado na pesquisa, do processamento da casca de coco se obtêm dois tipos de produtos, as fibras longas (30,0\% da casca) e as fibras curtas ou pó da casca de coco (70\% da casca), que se bem reaproveitados diminuem, consideravelmente, os transtornos ambientais provocados pelo seu descarte em lixões ou aterros sanitários (FONTENELE, 2005). 
Identificou-se que a tecnologia de processamento das cascas de coco verde foi desenvolvida pela Embrapa Agroindústria Tropical (Embrapa), em parceria com a metalúrgica Fortalmag, que realiza as ações de trituração, nas quais as cascas inteiras ou cortadas são processadas por uma máquina, que possui um rolo de facas fixas responsáveis pelo esmagamento da parte fibrosa do fruto; passando para o processo de prensagem, em que o material triturado é transportado para uma prensa rotativa horizontal, que extrai o excesso de líquido do produto triturado e a seleção, que após a prensagem, as fibras, que correspondem a $30 \%$ do produto final são separadas do pó, em uma máquina selecionadora, que utiliza marteletes fixos helicoidais e uma chapa perfurada (EMBRAPA, 2016).

De acordo com Fontenele (2005), o agronegócio do coco envolve diferentes atividades econômicas, que vão desde a produção agrícola, até sua distribuição nos mercados interno e externo, passando pelas etapas de processamento, embalagem ou envasamento, transporte e armazenamento. No decorrer desse processo são desenvolvidos diversos subprodutos a partir do aproveitamento, não só do fruto, mas também de várias partes da planta. Desse modo, entende-se que é possível identificar alguns aspectos relacionados à sustentabilidade, bem como ressaltar quais os membros da cadeia do Coco, o que contribui para uma visualização macro de como se comporta o setor. Assim, o Quadro 1 resume os principais achados desta pesquisa e serve como referência para outras pesquisas no setor.

Quadro 1: Cadeia Produtiva da Indústria do Coco

\begin{tabular}{|c|l|}
\hline Critérios & \multicolumn{1}{|c|}{ Cococultura } \\
\hline Membros da cadeia & $\begin{array}{l}\text { Produtores Agrícolas; Intermediários; Indústrias; } \\
\text { Distribuidores; Atacadistas; Varejistas; Cliente } \\
\text { final; Usina de biomassa; Embrapa Agroindústria } \\
\text { Tropical; Instituto ECoco; Prefeitura }\end{array}$ \\
\hline Ações de sustentabilidade & $\begin{array}{l}\text { Utilização de resíduos pela fabricação de produtos } \\
\text { (ex: mantas, tapetes, vasos); Biomassa } \\
\text { (combustível de caldeiras) }\end{array}$ \\
\hline
\end{tabular}

Fonte: Dados de Pesquisa (2016)

A partir das informações apresentadas no Quadro, percebe-se que a cadeia do Coco tem uma estrutura articulada, que poderia ser utilizada para estimular mais fortemente a sustentabilidade em sua dinâmica. No entanto, como destacado, as ações existentes focam apenas a dimensão ambiental (num contexto de reutilização) tanto na produção de novos produtos como de biomassa. Assim sendo, ainda existe uma demanda para focar aspectos sociais e em certo sentido também o econômico, pois pode haver maior engajamento dos envolvidos no desenvolvimento da localidade. Mesmo assim, mais ações ambientais ainda são necessárias já que como identificado na Embrapa um dos atuais problemas das indústrias está em dar a melhor destinação para a casca do coco, que se amontoa nas fazendas. A partir desta discussão, entende-se que em relação à sustentabilidade ainda existe um caminho a ser percorrido e trabalhado de acordo com as especificidades do setor.

\subsection{Membros da cadeia de produção do Caju e suas ações de sustentabilidade}


No que se refere à cadeia do caju, segundo o Sindicaju (2016), esta consiste na produção, industrialização, comercialização local e internacional dos consumíveis do caju, que são eles: a castanha de caju (fruto) e o pedúnculo (pseudofruto). O Ceará é atualmente o maior produtor de castanha de caju do Brasil e de acordo com o LSPA, a área plantada equivale a 384.905 ha $(64,69 \%$ da área plantada no Brasil), o que mostra grande potencial e importância dessa atividade para o Ceará (onde gera muitos empregos diretos e indiretos por meio da indústria e das fazendas, e como também sua importância ao Brasil. O caju após ser colhido tem suas partes separadas de acordo com o destino final, que podem ser: (1) o caju in natura, (2) a indústria da castanha de caju (esse mercado é mais conhecido por ter como destino o mercado externo), e (3) a indústria do pedúnculo (esse mercado é exclusivamente interno) (OLIVEIRA; IPIRANGA, 2009) (Ver Figura 2).

Figura 2. Cadeia de suprimentos do caju

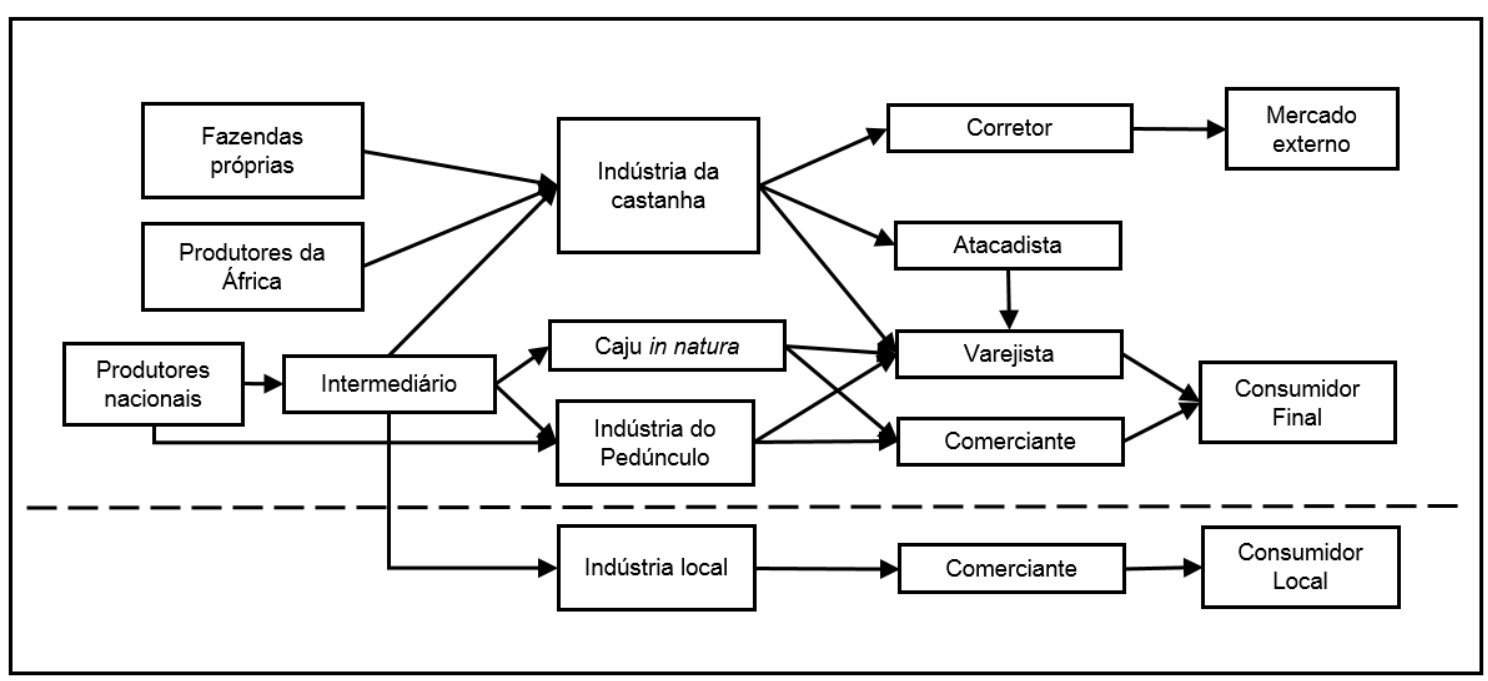

Fonte: Dados de pesquisa (2016)

A sequência de membros da cadeia, como na Figura anterior, começa pelos produtores nacionais e internacionais (da África), bem como as fazendas próprias. Vale salientar que existem outros membros de insumos que são responsáveis por facilitar a produção do fruto. Destaca-se neste momento que foram poucas as informações nos documentos que expôs a questão da importação da África, este dado foi coletado junto ao especialista de qualidade. Esta ação tem servido para minimizar os impactos da seca ocorrida nos últimos anos. Após a realização das colheitas pelos produtores, os cajus distribuídos para intermediários são repassados para três diferentes membros da cadeia produtiva (processadores), como mencionado anteriormente. Destaca-se, ainda, que tal intermediário é considerado como um membro indesejado, mas muito frequente na cadeia pelo seu contato direto com os produtores e indústria local.

Após o processo de transformação do caju, os produtos são repassados para o comércio, por meio de atacadistas, que então são transferidos para os varejistas e finalmente, vendidos para o consumidor final, e no caso do mercado externo, são levados aos corretores (brokers), que fazem a venda a seus parceiros importadores 
de outros países. Destaca-se ainda o papel dos comerciantes, que seriam os pequenos vendedores de caju in natura para a população. Este mesmo membro ainda assume dentro de um contexto mais informal o facilitador da venda de todos os produtos advindos do caju para o consumidor local, o que ocorre em feiras e mercados, de diferentes cidades e em especial em Fortaleza.

Por outro lado, o pedúnculo por ser o objeto secundário nessa cadeia de valor, é subaproveitado, em torno de $90 \%$, como informou o especialista da Embrapa. Levando em consideração esse alto nível de desperdício do pedúnculo, a Embrapa (2015) desenvolveu uma fórmula de hambúrguer que utiliza como matéria prima principal, a fibra do caju, que seria um subproduto de fábricas de suco a ser descartado. Com isso, tem-se um produto de origem vegetal que considerando todos os custos, sairia mais barato que todas as outras formas de hambúrguer vegetal, como também das de carne animal, criando um produto inovador, de baixo custo e baixo valor final, que adicionariam uma nova fonte de renda à empresa, onde estariam vendendo um produto ao invés de descarta-los conforme era realizado antes, aperfeiçoando sua competitividade.

Foi também identificado que a Embrapa foi uma organização de importância relevante para o agronegócio do caju por pesquisas realizadas desde 1965, através de outras empresas, e dos programas de implementação das descobertas juntamente com os produtores da cadeia. Uma descoberta muito importante foi a criação de cajueiros anão, que facilitam a colheita de caju por serem menores, aumentam a produção, alongam o período de safra e outros benefícios. Vários cajueiros foram doados a produtores para teste (EMBRAPA, 2015). Também foram criadas técnicas, como a de substituição da copa dos cajueiros, para poder aumentar o tempo de vida e produção dos pés de caju, pois o tempo de vida dos cajueiros gigantes (em torno de $95 \%$ da produção nacional) é em torno de 25 anos, e os cajueiros da produção nacional têm em média 20 anos, o que gera perda na produtividade e na qualidade do produto.

Outra ação de sustentabilidade que pode se destacar para o caju seria a Produção Mais Limpa (PML), que de acordo com Oliveira e Ipiranga (2009), destaca que se constitui em 3 níveis na empresa, que seriam elas: Tentativa de minimização de resíduos e emissões, pela modificação do produto/processo para maior produtividade (aumentar bens finais, reduzir resíduos), que seria por meio de modificação de tecnologias ou outras formas. No nível 2, tentativa de reutilização dos resíduos por meio de reciclagem interna. No nível 3, sendo a reutilização de resíduos e emissões por meio de reciclagem externa.

Durante a pesquisa pôde-se observar que há muitas pesquisas e inovações nessa área, gerada pela Embrapa, Nutec e outras instituições, que ficam primariamente no Ceará, o que faz com que o Ceará seja o Estado que mais possua inovações nesta área. Porém, apesar de todos os avanços na área, proporcionado pelas pesquisas, foi visto que a maioria dos conhecimentos gerados não chega à maioria dos elos da cadeia de produção e que quando são implementados, isso ocorre em baixa escala, seja por falta de crédito disponível para os agricultores, ou pelo não reconhecimento da importância de ser utilizado ou até mesmo por falta da facilidade de ter acesso a este conhecimento (OLIVEIRA; IPIRANGA, 2009).

Algumas áreas do setor do caju, principalmente para a que é exportada, é exigido de seus clientes no exterior, vários certificados de qualidade, ISO e outros 
atributos, portanto faz-se necessário aperfeiçoar a produção que segue para o exterior, o que agrega valor ao produto ofertado e os dá vantagem. Entretanto, para os consumidores do mercado interno essas características já não são tão importantes, o que pode gerar certo distanciamento dos membros da cadeia. Dessa forma, existe em certo sentido uma dificuldade para a integração da PML no modelo de gestão empresarial, que depende de uma mudança estrutural em todos os níveis da empresa, visto que se não houver comprometimento de toda a empresa para os devidos fins, serão utilizadas tecnologias fim-de-tubo para atingir o objetivo com o mínimo de esforço. Necessita-se maior engajamento pelos membros da cadeia.

Quadro 2: Cadeia Produtiva da Indústria do Caju

\begin{tabular}{|c|l|}
\hline Critérios & \multicolumn{1}{|c|}{ Cajucultura } \\
\hline $\begin{array}{c}\text { Membros da } \\
\text { cadeia }\end{array}$ & $\begin{array}{l}\text { Produtores nacionais e internacionais; Intermediários; } \\
\text { Processadores (Pedúnculo e Amêndoa); Corretor; Atacadista; } \\
\text { Varejista; Comerciante; Mercado consumidor; Sindicaju; } \\
\text { Embrapa. }\end{array}$ \\
\hline $\begin{array}{c}\text { Ações de } \\
\text { sustentabilidade }\end{array}$ & $\begin{array}{l}\text { Fabricação de produtos (ex: carne de hambúrguer); } \\
\text { Produção Mais Limpa; Doação de cajueiros anões (ênfase na } \\
\text { relação ambiental e econômico) }\end{array}$ \\
\hline
\end{tabular}

Fonte: Dados de Pesquisa (2016)

De acordo com as informações apresentadas acima o setor apresenta uma estrutura bem definida enquanto focada na cadeia produtiva, todavia diferente do Coco parece não haver tanta articulação entre os membros, o que dificulta a sustentabilidade. Embora algumas ações tenham sido identificadas nas dimensões ambiental e econômica, não ficou evidente durante esta pesquisa se há algum envolvimento com a dimensão social, o que torna dificultada a busca pela sustentabilidade na cadeia de suprimento. Mesmo assim, ações ambientais também não se demonstram tão evidentes neste momento, o que deve estimular que novos comportamentos surjam. É necessário haver maior articulação entre os membros, uma vez que como apresentado no referencial teórico e destacado por Silva et al. (2016), esta perspectiva pode emergir como aquele aspecto que impacta fortemente na SCS do setor de alimentos e modificar o contexto de observação da cajucultura.

\section{Considerações finais}

Com base nos dados analisados, entende-se que as duas cadeias estudadas buscam cultivar e comercializar as frutas de acordo com uma estrutura clara de interação entre determinados membros, e contribuir para o desenvolvimento contínuo do setor, preocupando-se com o futuro, utilizando métodos que ajudam a diminuir o impacto ambiental da produção. Porém, como identificado, o foco ainda está fortemente ligado às questões ambientais. Assim, os resultados de ações de sustentabilidade foram considerados, com esta pesquisa, pouco satisfatórios para a cajucultura e a cococultura. Apesar deste resultado, foram identificadas possíveis ações de sustentabilidade junto aos membros das duas cadeias de suprimento. É 
necessário observar que a produção de coco, apesar de não apresentar sindicato, tem maior tendência à articulação entre os membros do que a de caju, aspecto relevante de ser observado e considerado na discussão sobre SCS.

As duas cadeias de produção demonstram impacto na economia e no meio ambiente do Nordeste. Quanto ao impacto socioeconômico da cajucultura no Ceará e na região nordeste foi considerado muito importante por gerar em torno de 280 mil empregos (Nordeste) no campo e criar 30 mil empregos diretos e 100 mil indiretos no Estado (ARRUDA et al., 2011). Para o Instituto ECoco (2016), a cococultura é responsável pela geração de mais de 500 mil empregos diretos no Brasil e outra enorme quantidade de empregos indiretos. No ano de 2000 , correspondeu a $5 \%$ de toda agricultura nordestina. Assim, entende-se que tal aspecto pode vir a contribuir e ser considerada para a sustentabilidade, por estar preocupada em garantir no longo prazo a viabilidade e a continuidade da empresa, bem como em contribuir para o futuro bem-estar da sociedade. Algo que precisa de um maior debate.

Entende-se como limitação para esta pesquisa a dificuldade de identificação de forma detalhada das ações de sustentabilidade, o que pode ter restringido os resultados apresentados. Além disso, é uma limitação a ênfase nas ações centrais das cadeias sem observar em detalhes o que estas desenvolvem. Para sanar este aspecto, entrevistas foram realizadas, mas ainda é necessária uma pesquisa de campo a fim de investigar a fundo quais as práticas sustentáveis, que de fato, as agroindústrias cearenses estão utilizando para a melhor produção do coco, do caju e de seus derivados. É importante ponderar a sustentabilidade em todo o ciclo de vida do produto, bem como a relação existente e necessária entre todos os membros da cadeia de suprimento. Portanto, temas como articulação, integração, práticas, visão relacional, colaboração, orientação, além de aspectos pontuais de sustentabilidade, dentre outros, podem emergir como potenciais bases de pesquisa que podem ser utilizadas para se estudar a sustentabilidade em cadeias de suprimento.

\section{Agradecimentos}

Agradecimentos à Universidade de Fortaleza que por meio do Edital 06/2016 FEQ/UNIFOR está dando o suporte para o desenvolvimento desta pesquisa.

\section{Referências}

ABDALA, E. C.; BARBIERI, J. C. Determinants of Sustainable Supply Chain: an analysis of mensuration models of pressures and socio-environmental practices. Journal of Operations and Supply Chain Management, v. 7, n. 2. 2014.

ALICEWEB. Estatísticas. Disponível em: http://aliceweb.desenvolvimento.gov.br/ Acesso: Fev 2017

ALMEIDA, F. O bom negócio da sustentabilidade. Rio de Janeiro: Nova Fronteira, 2002.

ANDRADE, M. M. de. Como Preparar Trabalhos para Cursos de Pós-Graduação: Noções Práticas. 5. ed. São Paulo: Atlas: 2002. 
ARRUDA, J. B. F.; BOTELHO, B. D.; CARVALHO, T.C. Diagnóstico da cadeia produtiva da cajucultura: um estudo de caso. In Anais... XXXI Encontro Nacional de Engenharia de Produção, Belo Horizonte, MG. 2011.

BARDIN, L. Análise de Conteúdo. 4ª̣ ed. Lisboa: Edições 70, 2009.

BESKE, P., LAND, A., SEURING, S. Sustainable supply chain management practices and dynamic capabilities in the food industry: A critical analysis of the literature. International Journal of Production Economics, v. 152, p. 131-143, 2014.

BESKE, P.; SEURING, S. (2014). Putting sustainability into supply chain management, Supply Chain Management: an international journal, v.19, n.3, p. 322-331. 2014.

CARVALHO, A. P.; BARBIERI, J. C. Innovation and sustainability in the supply chain of a cosmetics company: a case study. Journal of technology management \& innovation, v. 7, n. 2, p. 144-156, 2012.

CARVALHO, A. P.; BARBIERI, J. C. Inovações socioambientais em cadeias de suprimento: um estudo de caso sobre o papel da empresa focal. RAI - Revista de Administração e Inovação, v. 10, n. 1, p. 232-256, 2013.

CAVALCANTE, L. C. Reestruturação Produtiva e Circuitos Espaciais da Produção de Coco no Ceará. In Anais... XXI Encontro Nacional de Geografia Agrária. Uberlândia, MG. 2012.

CLARO, P. B. O.; CLARO, D. P.; AMÂNCIO, R. Entendendo o conceito de sustentabilidade nas organizações. Revista de Administração (FEA-USP), v.43, n.4, p.289-300, 2008.

CODEVASF - Companhia de Desenvolvimento dos Vales do São Francisco e do Parnaíba. Cajuína do Piauí é patrimônio cultural brasileiro. 2014. Disponível em: http://www.codevasf.gov.br/noticias/2014/cajuina-do-piaui-e-patrimonio-culturalbrasileiro/ Acesso: Fev/2017.

CRESWELL, J. W. Projeto de pesquisa: métodos qualitativo, quantitativo e misto. 2. ed. Porto Alegre: Artmed/Bookman. 2007.

DE CASTRO, A M G; LIMA, S M V; CRISTO, C. M. P.N.. Cadeia produtiva: marco conceitual para apoiar a prospecção tecnológica. In Anais... XXII Simpósio de Gestão e Inovação Tecnológica. Salvador: BA. 2002.

ELKINGTON, J. (eds.) Cannibals with forks: the triple bottom line of 21st century business [reprint]. Oxford: Capstone. 2002.

ELKINGTON J. Breakthrough Forewords. 2014. Disponível em: http://www.breakthroughcapitalism.com/files/volans-breakthrough-market-report.pdf Acesso: Dez 2016.

EMBRAPA - Empresa Brasileira de Pesquisa Agropecuária. Beneficiamento Da Casca De Coco Verde. 2016. Disponível em: <http://www.ceinfo.cnpat.embrapa.br/arquivos/artigo_3830.pdf> Acesso: Ago 2016. 
EMBRAPA - Empresa Brasileira de Pesquisa Agropecuária. Hambúrguer de caju aproveita fibra descartada da Indústria. 2015. Disponível em: $<$ https://www.embrapa.br/web/portal/busca-de-noticias//noticia/6659300/hamburguer-de-caju-aproveita-fibra-descartada-da-industria> Acesso: Ago 2016.

FIEC - Federação das Indústrias do Estado do Ceará e Centro Internacional de Negócios do Ceará. Mini Estudo Setorial - Castanha de Caju Outubro de 2015. $2015 . \quad$ Disponível em: $<$ http://www1.sfiec.org.br/sites/cin/files/files/castanha outubro.pdf> Acesso: Ago 2016.

FONTENELE, R. E. S. Cultura Do Coco No Brasil: Caracterização Do Mercado Atual E Perspectivas Futuras. In Anais... XLIII Congresso da Sociedade Brasileira de Economia e Sociologia Rural. Ribeirão Preto, SP. 2005.

GIMENEZ, C.; TACHIZAWA, E.M. Expending sustainability to suppliers: a systematic literature review. Supply Chain Management: an international journal, v. 17, n. 5, p. 531-543. 2012.

GIORDANO, S. R. Gestão Ambiental no Sistema Agroindustrial. In: ZYLBERSZTAJN, D.; NEVES, M. F. Economia e Gestão dos Negócios Agroalimentares: indústria de alimentos, indústria de insumos, produção agropecuária, distribuição. São Paulo: Pioneira Thomson Learning, 2005.

GOLD, S. Sustainable supply chain management research in Brazil. In: SILVA, M. E.; NASCIMENTO, L. F. M. (Org.). Sustentabilidade em Cadeias de Suprimento: entre teoria e prática. ePUB (Online). Porto Alegre, RS. 2016.

GOLICIC, S.L.; SMITH, C.D. A meta-analysis of environmental sustainable supply chain management practices and firm performance. Journal of Supply Chain Management, v. 49, n. 2, p. 78-95. 2013.

GONÇALVES-DIAS, S. L. F.; LABEGALINI, L.; CSILLAG, J. M. Sustentabilidade e cadeia de suprimentos: uma perspectiva comparada de publicações nacionais e internacionais, Produção, 22 (3), p.517-533, 2012.

Instituto Ecoco. A Cadeia Produtiva do Coco e o Resíduo Sólido. 2016. Disponível em: <http://www.institutoecoco.com.br/cadeia-produtiva-do-coco.html> Acesso: Ago 2016

MARCONI, M. A.; LAKATOS, E. M. Fundamentos de metodologia cientifica. São Paulo: Atlas. 2010.

Ministério da Agricultura, Pecuária e Abastecimento - MAPA. Sistema de produção para a cultura do coqueiro. FONTES, H. R.; FERREIRA, J. M. S.; SIQUEIRA, L. A. (Org.). Aracaju: Embrapa Tabuleiro Costeiro, 2002. 
MORAIS, D. O. C.; BARBIERI, J. C. Gestão da cadeia de suprimento com foco em sustentabilidade e inovação: perfil das publicações em revistas e congressos brasileiros. In Anais... XVII Encontro Internacional de Gestão Empresarial e Meio Ambiente. São Paulo: SP. 2015.

OLIVEIRA, L. G. L., IPIRANGA, A. S. R., A Inovação Sustentável e a Dinamização do Sistema Local do Agronegócio do Caju Cearense. Revista Contemporânea de Economia e Gestão, v. 7, n. 1, p. $55-68,2009$.

PAGELL, M.; WU, Z. Building a more complete theory of sustainable supply chain management using case studies of 10 exemplars. Journal of Supply Chain Management, v. 45, n. 2, p. 37-56. 2009.

PAGELL, M.; SCHEVCHENKO, A. Why research in sustainable supply chain management should have no future. Journal of Supply Chain Management, v. 50, n. 1, p. 1-32. 2014.

PIRES, S. Gestão da cadeia de suprimento: conceitos, estratégias, práticas e casos. São Paulo: Atlas, 2007.

PUSAVEC, F.; KRAJNIK, P.; KOPAC, J. Transitioning to sustainable production - Part I: application on machining technologies. Journal of Cleaner Production, v. 18, p. 174-184, 2010.

REBELLO, F. K.; REALE FILHO, H. B.; FIGUEIREDO, R. N. Diagnóstico e perspectiva econômica da cadeia produtiva do coco-da-baía no Estado do Pará. In: GRAÇA, Hélio. (Org.). O meio amazônico em desenvolvimento: exemplos de alternativas econômicas. Belém: Banco da Amazônia, 2003, p. 133-198.

ROCHA, F. B. A.; CAMPOS, M. C.; COLOMBO, C. R.; CELESTINO, J. E. M. Gestão de resíduos como ferramenta aplicada ao beneficiamento do coco verde. In Anais... XXX Encontro Nacional de Engenharia de Produção, 2010.

SANTOS, A. W. L.; LIMA, I. V.; SOUZA, I. B. F.; FRANSCISCO, J. L.; FRANCO, P. A.; OLIVEIRA, P. F.; SILVA, S. C. R.; VALERIO, T. N.; SILVA, A. V. Piso Produzido A Partir De Fibras Vegetais. E-xacta, Belo Horizonte, v. 4, n. 2. 2011.

SARTORI, S.; LATRÔNICO, F.; CAMPOS, L. M. S. Sustentabilidade e Desenvolvimento Sustentável: uma taxonomia no campo da literatura, Ambiente \& Sociedade, n. 1, p. 1-22. 2014.

SEURING, S.; MÜLLER, M. From a literature review to a conceptual framework for sustainable supply chain management. Journal of Cleaner Production, v(16), p. 1699-1710, 2008.

SHARFMAN, M. P., SHAFT, T. M. \& ANEX JR., R. P. The Road to Co-operative Supply-Chain Environmental Management: Trust and Uncertainty Among Pro-Active Firms. Business Strategy and the Environment, v. 18, 1-13, 2009 
SILVA, D. B. Sustentabilidade no agronegócio: dimensões econômica, social e ambiental. Comunicação \& Mercado/UNIGRAN - Dourados - MS, v. 01, n. 03, p. 2334, 2012.

SILVA, M. E.; ALVES, A. P. F.; DE BARCELLOS, M. D. Sustainable Beef: práticas para a sustentabilidade na cadeia da carne bovina gaúcha. Desenvolvimento em Questão, n. 35, p. 274-306, 2016.

SILVA, M. E.; OLIVEIRA, E. M.; NASCIMENTO, L. F. Mapeamento de stakeholders sob a perspectiva da sustentabilidade: uma desk research com organizações gaúchas. Revista Metropolitana de Sustentabilidade, v. 5, n. 1, 2015.

SILVESTRE, B. Sustainable supply chain management in emerging economies: Environmental turbulence, institutional voids and sustainability trajectories. International Journal of Production Economics, v. 167, p. 156-169. 2015.

SILVESTRE. B. Sustainable supply chain management: current debate and future directions. Gestão e Produção. 2016. http://dx.doi.org/10.1590/0104-530X2202-16

SINDICAJU. Sindicato das Indústrias de Beneficiamento de Castanha de Caju e Amêndoas Vegetais do Estado do Ceará. Cadeia Produtiva. 2016. Disponível em: <http://sindicaju.org.br/perfil-do-setor/cadeia-produtiva/>. Acesso: Ago 2016.

SOUZA, B. A.; MORAIS, R. E. S. Agronegócio, análises e reflexões sobre desenvolvimento e sustentabilidade no Estado de Goiás. Revista PLURAIS/Virtual, v. 2, n. 1, 2012.

TAKAHASHI, A. R. G.; SANTA-EULALIA, L. A. de; GANGA, G. M. D.; ARAUJO, J. B.; AZEVEDO, R. C. Projeto de cadeia de suprimentos ágeis e verdes: estudos exploratórios em uma empresa de bens de consumo não duráveis. Production, v. 25, n. 4, p. 971-987. 2015.

TOUBOULIC, A.; WALKER, H. Love me, love me not: a nuanced view on collaboration in sustainable supply chains. Journal of Purchasing \& Supply Management, 21, 2015.

WCED - World Commission on Environment and Development. Report Our common future. Genebra, 1987. Disponível em: < http://www.un-documents.net/wcedocf.htm>. 